\title{
Aerodynamic Performance Characterization and Static Structural Analysis of Slotted Propeller: Part A Effect of Position
}

\author{
Aravind Seeni \\ School of Aerospace Engineering, University of Science Malaysia, Engineering Campus, Nibong Tebal 14300, Penang, \\ Malaysia
}

Corresponding Author Email: aravind.seeni@student.usm.my

https://doi.org/10.18280/mmep.060417

Received: 9 September 2019

Accepted: 10 December 2019

\section{Keywords:}

slotted propeller, computational fluid dynamics, static structural, low Reynolds number, APC slow flyer, ANSYS fluent, ANSYS mechanical

\begin{abstract}
In this paper, novel slotted propeller blade design performance is presented in terms of thrust coefficient, power coefficient and efficiency by utilizing ANSYS Fluent. The effects of slotted positions were discussed with respect to baseline APC Slow Flyer 10' $\mathrm{x}$ 7' configurations. Seven slot locations with respect to chord length, $12.5 \%, 25 \%, 37.5 \%, 50 \%$, $62.5 \%, 75 \%$ and $87.5 \%$ were tested. The result shows that introduction of slot along the propeller blade increases the thrust coefficient, with range of $0.1 \%$ to $4.74 \%$ for low advance ratio. However, increase in thrust coefficient also causes increase in power coefficient, ranging from $10.38 \%$ to $44.59 \%$ compared to baseline design, hence reducing propeller efficiency.

In addition, structural integrity of the blade was tested. Pressure distribution of the propeller blade demonstrated higher pressure on the back section, and lower pressure at the front section which produces thrust. In addition, the result shows that pressure distribution are highly influenced by changes of advance ratio. The analysis shows that the propeller design managed to withstand stress and strain breaking point when operated at high advance ratio.
\end{abstract}

\section{INTRODUCTION}

Continuous development and optimization of Unmanned Aerial Vehicle (UAV) throughout the years are mainly contributed by rapid growth of the system and components required. This is due to the availability of advance lightweight material, microelectronics system, allowing generation of enhanced efficiency UAV. Thus, allowing emerging civil market to venture into the utilization of UAV aiming for various missions [1-3].

Apart from that, efficiency of a UAV is significantly influenced by the propeller. Thus, the propeller selected for any UAV need to be able to cater aerodynamic requirements of the UAV. Currently, selections of propeller blade are concentrated on off-shelf blade design based on its availability and economical advantage. Therefore, more efforts are required to find suitable propeller blade based on the UAV design.

In addition, implementation of unconventional blade design such as slotted, serrated, tubercle and adaptive structure are barely used in any UAV. This is due to lack of study available for the unconventional design specifically for low Reynolds number small-scale propeller. Therefore, this study aims to provide an extensive research on novel slotted designs for small scale propeller blade operating at low Reynolds number, typically less than 100,000 measured at $75 \%$ chord blade station.

The objective of this work is to design and study the performance of slotted propeller blade operating at low Reynolds number. The study is divided into two main analysis, which includes aerodynamic performance and static structural analysis. The flow simulations are performed through three- dimensional computational fluid dynamic software (FLUENT) to determine the thrust coefficient, power coefficient and overall efficiency measured in advancing flow conditions. Meanwhile ANSYS Mechanical Static Structural are used to determine highest stress and maximum deformation experienced by the propeller blade. Next section discussed the method, and design available for UAV, marine ship and wind turbine, as these blades working principle is similar, varying only shape for working conditions adaptations $[4,5]$.

Extensive research has been done for the conventional design of propeller blade, revolving around the standard parameter including diameter, pitch, blade shape and chord length. Thus, the opportunity to further improve the design of propeller blade is by inducing more advance design, such as serrated, slotted, tubercle and adaptive structure. Liu et al. [6] performed a study to investigate the impact of serration on leading and trailing edge of airfoil. The result shows conditional performance due to major influence of serration design and airfoil type. Apart from that, Chong [7] discussed various serration design, including $\mathrm{M}$-shaped, wavy and sawtooth. Based on the analysis, it is proven that serration influence boundary layer characteristics.

Ibrahim et al. [8] tested two advance blade design, including slotted and tubercle for wind turbine. The result shows that slotted design performed better than straight blade in terms of power, meanwhile tubercle design performance deplete. Lin et al. [9] compare the performance of tubercle blade wind turbine with straight design, the result shows improvement of $0.38 \%$ to $2.31 \%$ increase in thrust. In addition, Riyadh Belamadi [10] study the performance of slotted wind turbine airfoils. Both leading edge and trailing edge design were tested, which gives 
the results that implementation of slotted design does not always lead to performance improvements, as it depends on the position and size of the slots.

There are two main methods available to determine the performance of a propeller, including experimental and numerical method. Apart from experimental analysis, numerical analyses are now commonly selected for performance analyses among researchers [11-13]. This is due to its capability to determine wide variety of results, such as forces and contours. In most research, integration of both methods was used for validation of numerical method by comparing with corresponding experimental results

For experimental method, propeller blade is tested in wind tunnel. Brandt et al. [14] performed experimental study to determine the performance of 79 small scale low Reynolds number propeller with variation of rotational speed. In addition, Deters et al. [15] performed a similar experimental study for 27 different type of propeller to study the influence of Reynolds number on propeller blade performance.

Subhas et al. [16] performed a numerical study to study the performance of ship propeller by using CFD method, utilizing multiple reference frame (MRF) method. The results obtained were compared with experimental analysis, with maximum and minimum difference of 0.0013 and 0.001 respectively. Wang et al. [17] performed a study to determine performance of propeller blade by using CFD by incorporating transitional analysis. In addition, Benini [18] utilized CFD Fluent to determine the performance of marine propeller. The result shows slight discrepancy with experimental data, maximum of $5 \%$. Tian [19] study the performance of wind turbine using Fluent, utilizing sliding mesh method to incorporate blade rotation. The result shows that the error between experimental and numerical data is below $5 \%$, which proves that numerical method is acceptable for performance prediction.

Apart from propeller performance, reliability of a propeller blade also depends on its structural integrity. Rao et al. [20] performed a stress analysis on composite propeller by using finite element analysis (FEA) using ANSYS. The study discussed and proposed the methodology to design and analyse composite and metal propeller blade, in terms of maximum deformation and normal stress. Yeo et al. [21] predict blade stress distribution for marine propeller blade through FEA. The analysis utilizes pressure distribution along the blade, to determine the highest stress and maximum blade deflection. Additionally, Das et al. [22] did a study to compare blade performance of the blade before and after deformation. The study found that the performance is not affected as the blade is rigid enough, which causes very minimal blade deformation. Kishore et al. [23] compare structural performance of two different material for propeller blade, by analysis through ANSYS. Von-mises maximum stress and strain, and total deformation data were collected. The results obtained from the analyses were compared with the material mechanical properties.

\section{METHODOLOGY}

In this study, off-shelf APC Slow Flyer 10' x 7' propeller blade is set as standard baseline design, due to the availability of experimental data. Detail on APC Slow Flyer is further explained in the next section. As mention previously, this study focuses on two main analysis, which includes aerodynamic performance and static structural analysis. First, numerical simulation of baseline design APC Slow Flyer is performed using the commercially available ANSYS Fluent software. This is intended to validate the method of numerical setup to extract propeller performance characteristics including thrust coefficient, power coefficient and efficiency. The numerical results obtained from the numerical analysis are compared with experimental data available $[15,24]$. Then, by using the validated method, similar analyses were done for newly developed slotted propeller blade design. The results were then compared with baseline APC Slow Flyer to determine the performance improvements of novel slotted blade design.

To determine the structural integrity, the best performance slotted design undergo further analyses by utilizing ANSYS Static Structural, to estimate maximum stress, maximum strain and total deformation under pressure.

\subsection{Propeller model}

APC Slow Flyer is a small scale two bladed- propeller, with the diameter (D) of $0.254 \mathrm{~m}$. As described by the manufacturer, this blade is made up from two different airfoils with Eppler E63 near the hub and Clark-Y near the tip. The propeller geometrical (Figure 1) shows the three-dimensional model of the propeller created using CATIA v5.

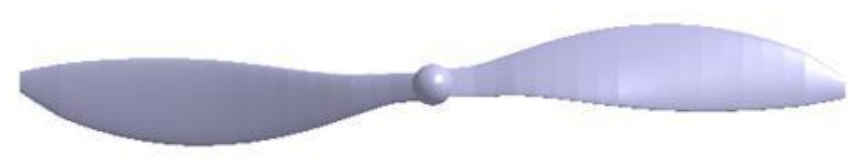

Figure 1. APC slow flyer 10’ x 7' baseline design

Table 1. Summary of computational parameters

\begin{tabular}{cc}
\hline Parameter & Description \\
\hline Inlet distance (Stationary region) & $4 \mathrm{D}$ \\
Outlet distance (Stationary region) & $4 \mathrm{D}$ \\
Enclosure (Rotating Region) & $0.4 \mathrm{D}$ \\
Diameter (Rotating Region) & $1.1 \mathrm{D}$ \\
Turbulence model & Standard k- $\omega$ \\
Fluid & Air \\
Blade motion type & Mesh motion(rotational) \\
Relative specification & Absolute \\
Reference frame & Multiple Reference Frame \\
Inlet boundary type & Velocity Inlet \\
Velocity inlet & (Refer Table 2) \\
Outlet boundary type & Outflow \\
Residual error & $1 \times 10^{-6}$ \\
Pressure-velocity coupling & SIMPLE Scheme \\
Gradient & Least Squares Cell Based \\
Interpolating scheme (momentum) & Second Order Upwind \\
Interpolating scheme & First Order Upwind \\
(Turbulence kinetic energy) & \\
Interpolating scheme & First Order Upwind \\
(Specific dissipation rate) &
\end{tabular}

\subsection{Computational fluid dynamics (CFD)}

\subsubsection{Computational parameters}

The computational parameters used for this study are tabulated in Table 1. The computational domain is divided into stationary region, and rotating region. The stationary domain is box-like design imitating wind tunnel test sections. The distance used for the stationary region is 4D upstream and 4D downstream, to prevent recirculation of flow in the rotating 
region that will influence the result of the analysis. The domain is defined and illustrated in Figure 2(a).

Meanwhile the rotating region is set to be $0.4 \mathrm{D}$ thickness with 1.1D diameter of enclosure. The propeller blade is embedded in the cylindrical rotating domain as shown in Figure 2(b). The rotation of this domain was achieved with Multiple Reference Frame.

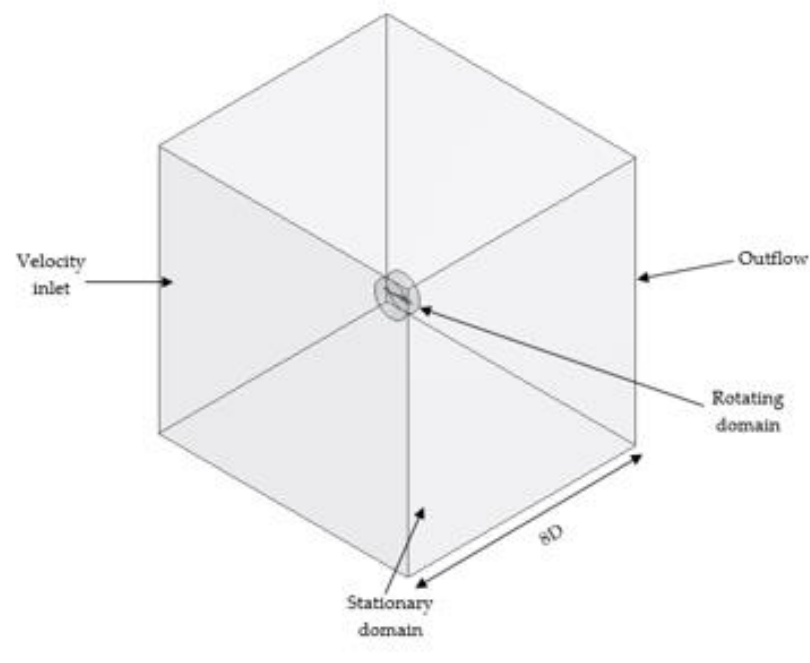

(a)

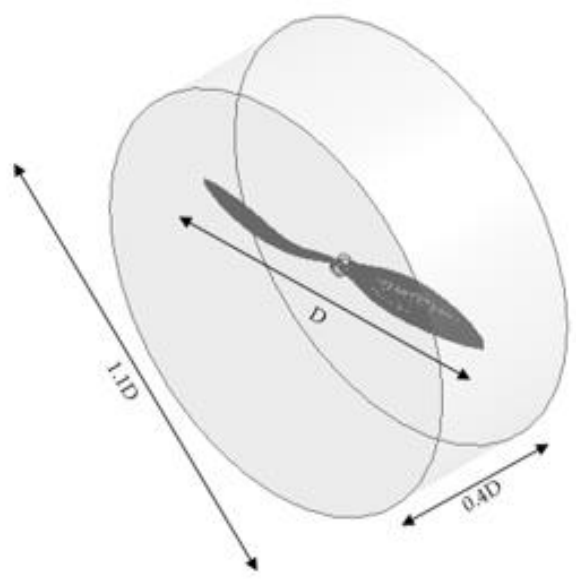

(b)

Figure 2. Flow domain and boundary conditions. (a) Stationary region flow domain. (b) Rotating region flow domain

Table 2. Simulation flow conditions

\begin{tabular}{cc}
\hline Advance coefficient, J & Free stream velocity $(\mathrm{m} / \mathrm{s})$ \\
\hline 0.192 & 2.4384 \\
0.236 & 2.9972 \\
0.282 & 3.5814 \\
0.334 & 4.2418 \\
0.383 & 4.8641 \\
0.432 & 5.4864 \\
0.486 & 6.1722 \\
0.527 & 6.6929 \\
0.573 & 7.2771 \\
0.628 & 7.9756 \\
0.659 & 8.3693 \\
0.717 & 9.1059 \\
0.773 & 9.8171 \\
0.799 & 10.1473 \\
\hline
\end{tabular}

\subsubsection{Mesh generations}

The grid is fully tetrahedral unstructured meshing in both stationary and rotating region. The selection of fully tetrahedral mesh is based on the justification that the grids have the capabilities to discretize complex geometries with minimum user intervention. In addition, it requires less computational time and manages to capture the boundary layer condition to ensure satisfactory analysis. To capture the boundary layer better, the meshing is more refine along the blade and gradually increase towards the stationary region. This is to ensure more meshing is concentrated along the blade region, as it influences the accuracy of the analysis, rate of convergence and computational time required.

\subsubsection{Boundary conditions}

The analyses were conducted for range of advance ratio, with variance of freestream velocity and fixed rotational speed of 3008 RPM. On the inlet flow domain, the inlet velocity is set, as tabulated in Table 2. Turbulence intensity is set to be
$0.1 \%$, based on the experimental analysis measured by $[14,15$, 24].

At the outlet boundary condition, it is set as outflow. Outflow is selected for the condition in which there is no information on the exit flow such as velocity or pressure prior to the analysis. In addition, the rotation of the rotating domain was achieved with Multiple Reference Frame (MRF) by incorporating rotational speed of the propeller. MRF is most suitable for the analysis that required interaction between two regions, one which operating at stationary freestream velocity, and another region operating at specific rotational speed. The use of MRF approach is limited to applications where there are no strong transient interactions taking place. In the present study, the use of MRF is sufficient since the flow is relatively uncomplicated in the interface between moving and stationary zones.

The pressure-coupling is achieved by using SIMPLE (Semi Implicit Method for Pressure Linked Equations) algorithm. Second order upwind was applied for momentum interpolating scheme, and first upwind scheme for turbulence kinetic energy and specific dissipation rate interpolation scheme.

\subsection{Static structural analysis}

In this computational analysis, structural analysis of the propeller blade was investigated by utilizing ANSYS Static Structural Workbench. Sections below describe the setup required to determine von-Mises maximum stress, von-Mises maximum strain and total deformation.

\subsubsection{Engineering data}

For this analysis, the material used are long fiber thermoplastic, specifically $60 \%$ long strand glass fiber reinforced nylon 6 Natural, similar with APC Slow Flyer 10 ' $x 7$ ' propeller blade. The mechanical properties data are collected from the manufacturer site [25]. The details of the material properties are listed in Table 3 . 
Table 3. Material properties

\begin{tabular}{cc}
\hline Property & Value \\
\hline Density & $1690 \mathrm{~kg} / \mathrm{m}^{3}$ \\
Young's Modulus & $19500 \mathrm{MPa}$ \\
Poisson's Ratio & 0.44 \\
Stress at break & $250 \mathrm{MPa}$ \\
Strain at break & $1.58 \%$ \\
\hline
\end{tabular}

\subsubsection{Meshing}

Once the slotted propeller model is transferred into the workbench, the mesh is generated with mechanical physical preferences. In this analysis, fully unstructured tetrahedral mesh was also implemented throughout the surface. Curvature advance size function was employed allowing better mesh generation. The number of elements created is 206,358 and number of nodes created is 364,238 .

\subsubsection{Boundary conditions}

Pressure magnitude along the propeller blade can be determined from CFD analysis. Pressure acted on the propeller blade will cause stress distribution along the blade and deformation, which results in performance reduction or subjected to material failure.

Structural analyses are conducted for slotted blade design for rotating speed of 3008 RPM for a range of operational velocity. This is based on the understanding that pressure generated during operation may differ based on freestream velocity. Thus, range of safe operational speed of the propeller blade need to be established, to prevent material failure.
Maximum stress generated is compared with tensile stress at failure of the material, which is $250 \mathrm{MPa}$.

\subsection{Numerical method verification and validation}

\subsubsection{Grid dependency study}

A grid resolution study was conducted to determine optimize grid for propeller performance predictions. Five grids size, referred as standard, coarse, mid, mid-fine, fine were generated. The details of the grid generated are tabulated in Table 4. Figure 3 shows surface mesh of the propeller blade. The analyses were conducted at advance ratio of 0.628 . The grid independence study for propeller is conducted by increasing the mesh size in suitable steps to find the out the appropriate mesh size suitable for the study. In order to perform this, a condition on advance ratio needs to be assumed, as this study cannot or need not be performed for all advance ratio conditions. In this case, the assumed advance ratio is 0.628 .

Table 4. Meshing details for baseline design

\begin{tabular}{cccc}
\hline Mesh & Cells & Faces & Nodes \\
\hline Standard & 380087 & 775533 & 70738 \\
Coarse & 1060142 & 2161896 & 197907 \\
Mid & 2006921 & 4087759 & 371637 \\
Mid-Fine & 3039047 & 6196556 & 564252 \\
Fine & 4093554 & 8340019 & 797621 \\
\hline
\end{tabular}

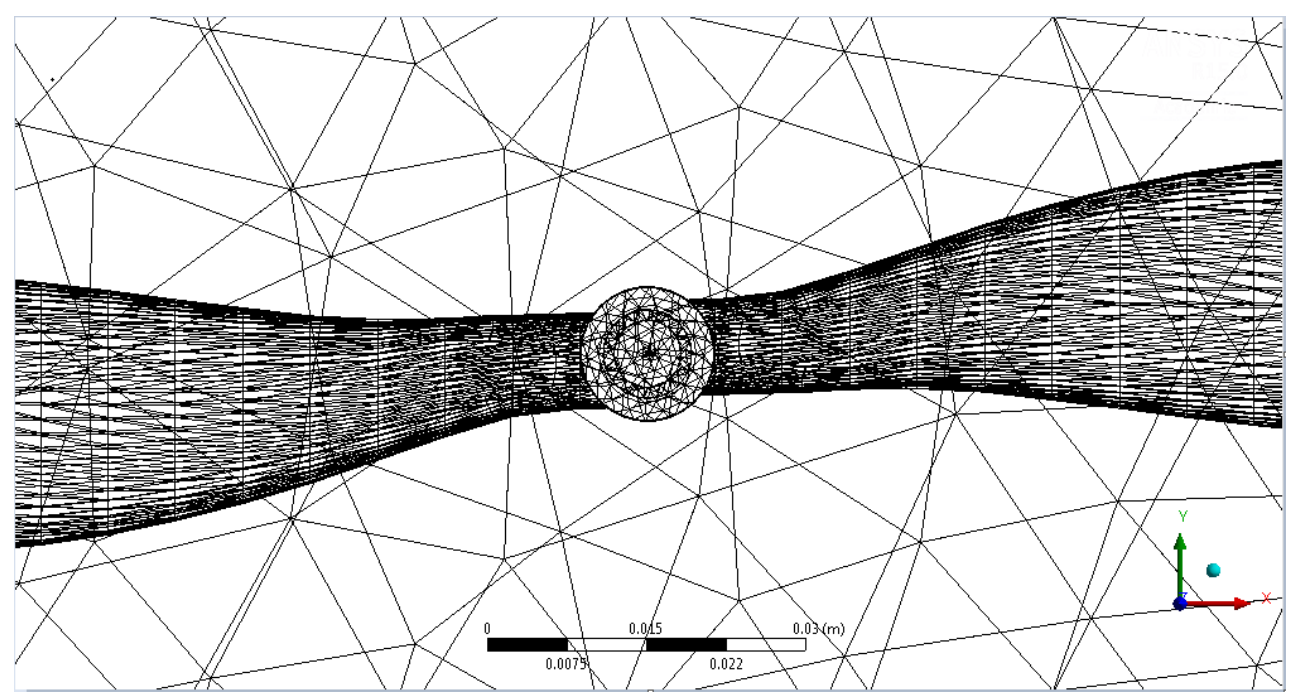

(a)

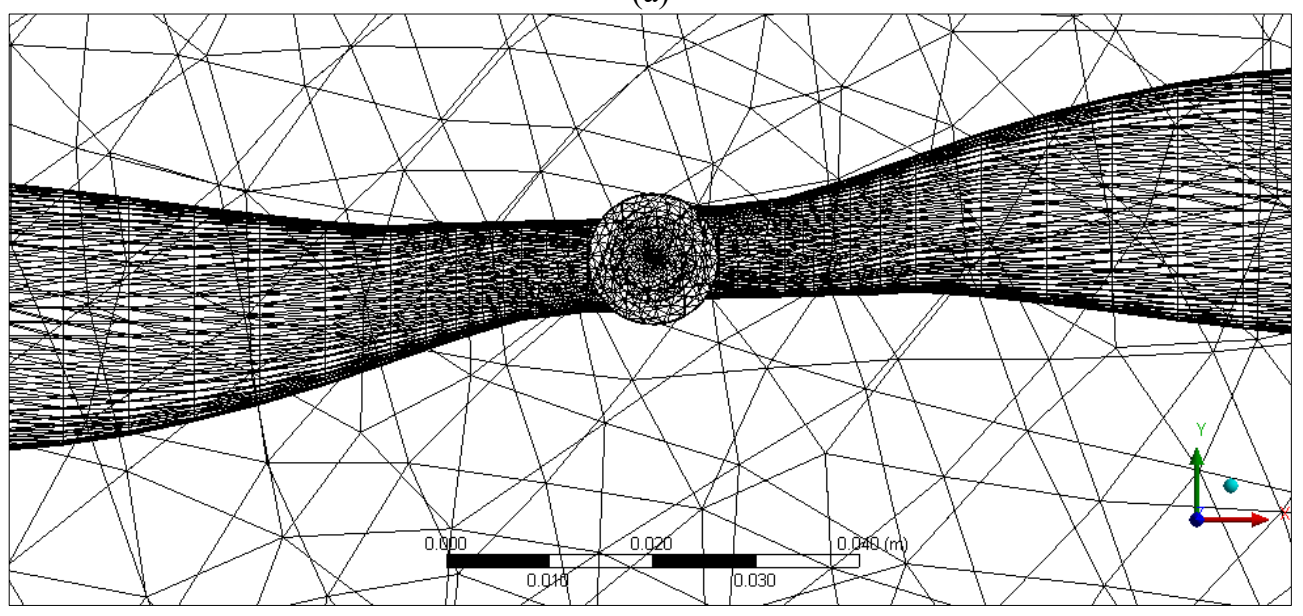

(b) 


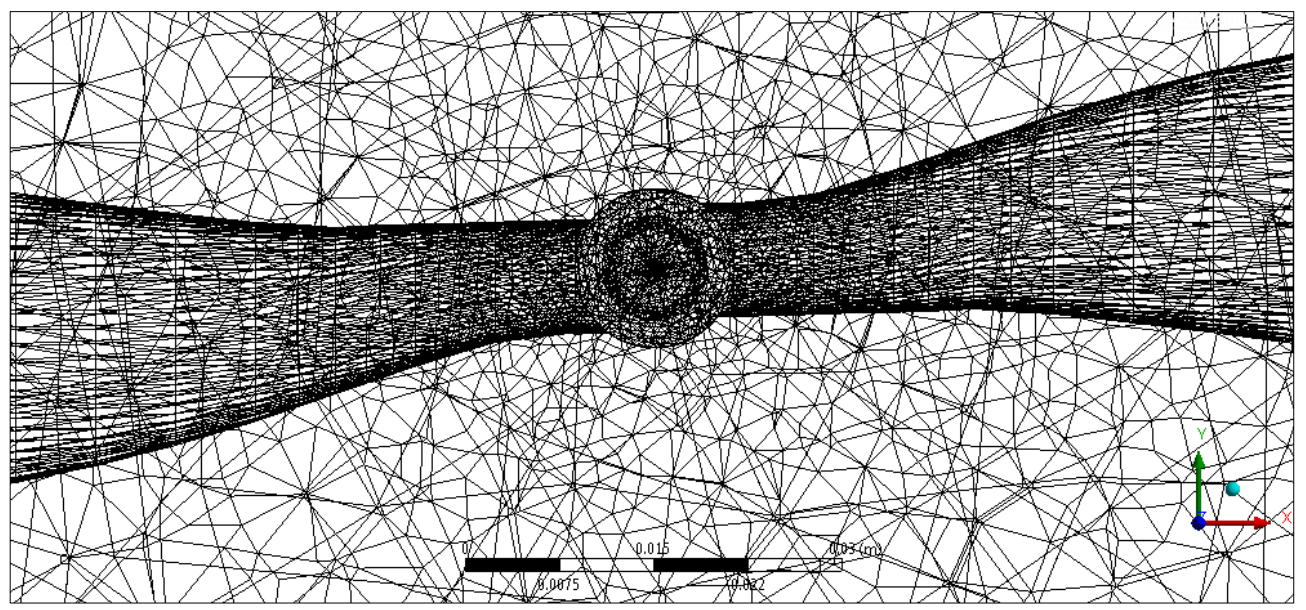

(c)

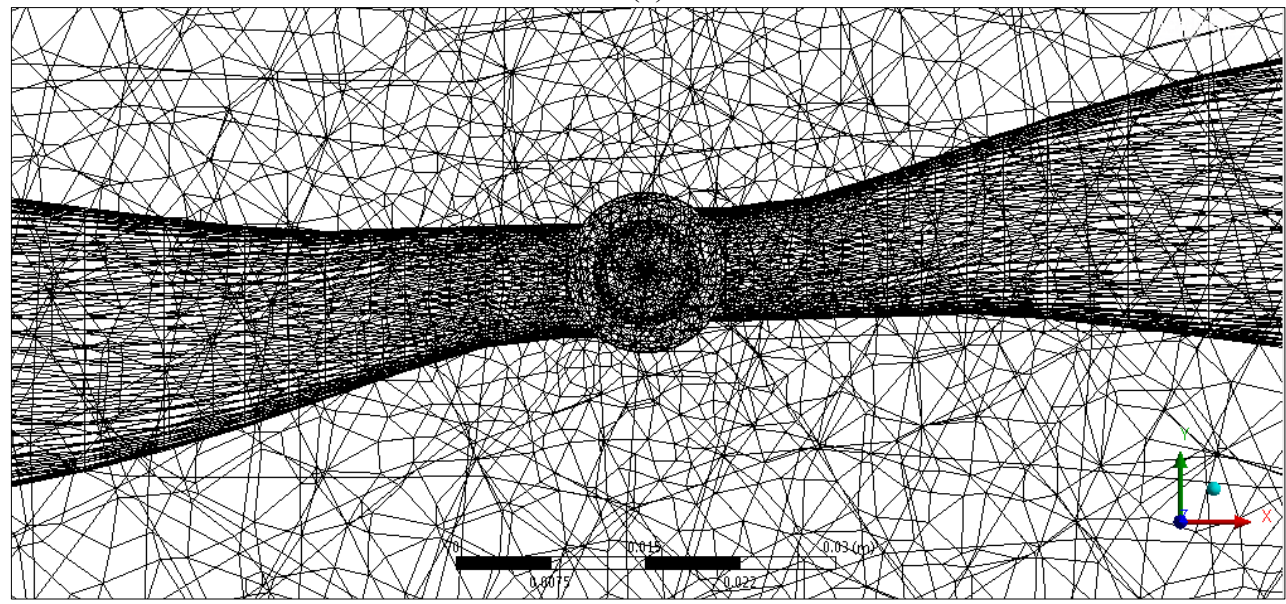

(d)

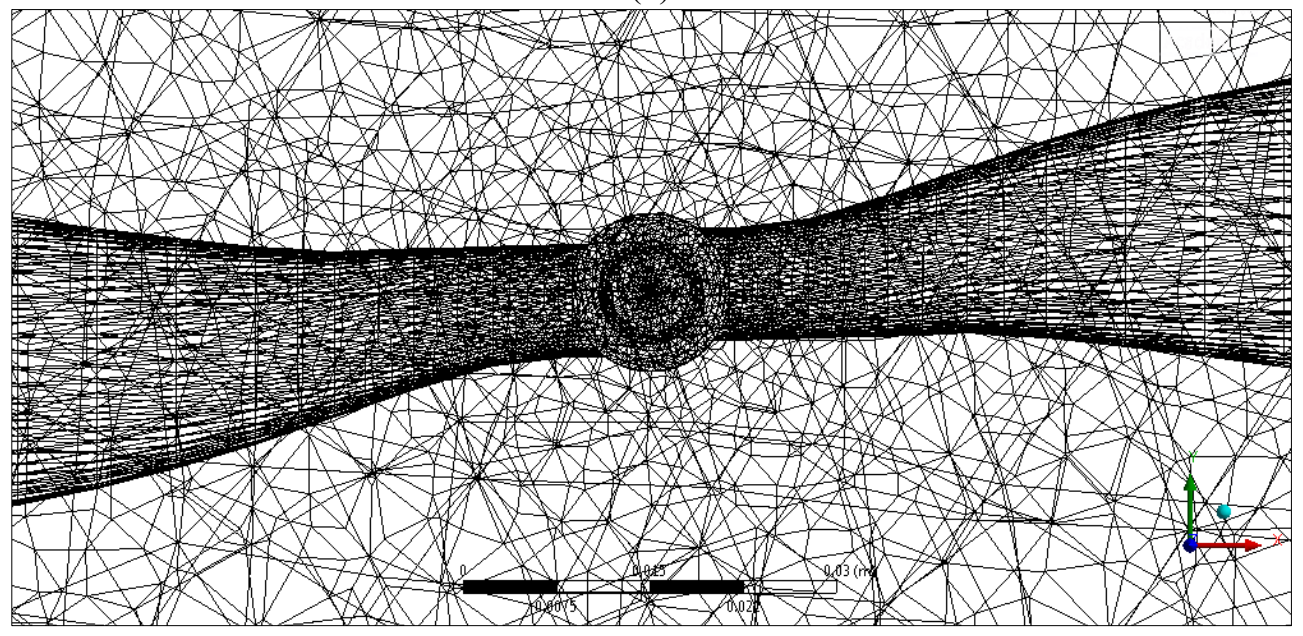

(e)

Figure 3. APC Slow Flyer 10’ x 7' surface meshes. (a) Standard mesh (b) Coarse mesh (c) Mid-mesh (d) Mid-Fine mesh (e) Fine mesh

\subsubsection{Turbulence model}

To validate the results, three different turbulence models were tested, including Standard k- $\varepsilon$, Standard k- $\omega$, and SST k$\omega$. The best model that may predict the propeller performance will be further used throughout the study.

\subsection{Slotted propeller blade design}

Slotted propeller blade designs were tested in this study, with the intention of increasing the performance of the propeller blade through improvements of propeller performance. This improvement can be observed either by increase in thrust, decrease in power coefficient or both. The implementation of slot in the propeller blade is expected to influence the flow around the propeller.

Figure 4 shows the slotted blade design analyzed in this study. 3D structure of same with slot in different locations is illustrated in Figure 5. To determine the influence of blade position on the propeller performance, chord length of the blade remains unchanged based on baseline APC Slotted Slow Flyer and the slot width is fixed for every slot position. The slot position is altered based on $12.5 \%$ increment with respect to the chord length. Thus, the analysis is carried out for seven blade locations, specifically $12.5 \%, 25 \%, 37.5 \%, 50 \%, 62.5 \%$, 


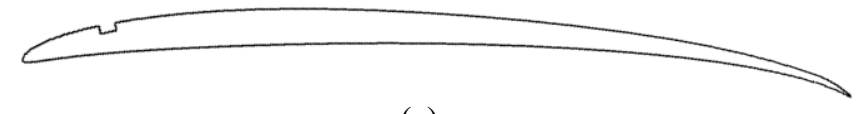

(a)

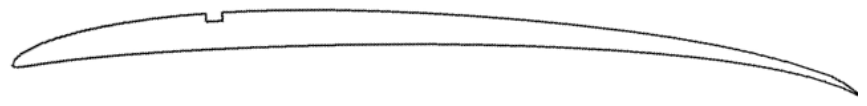

(b)

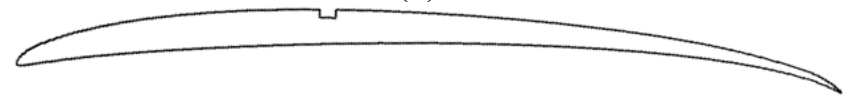

(c)

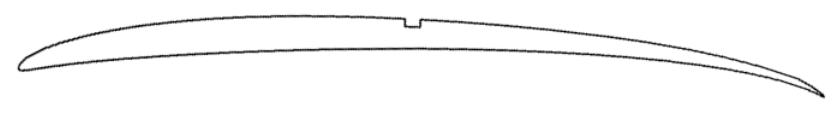

(d)

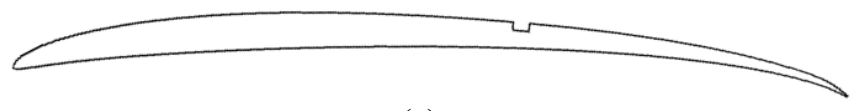

(e)

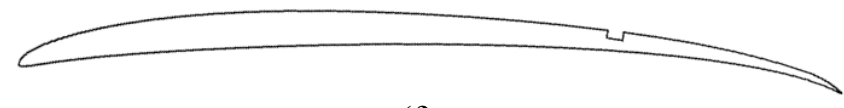

(f)

(g)

Figure 4. Slotted blade cross-section on the blade tip. (a) $12.5 \%$, (b) $25 \%$, (c) $37.5 \%$, (d) $50 \%$, (e) $62.5 \%$, (f) $75 \%$, (g) $87.5 \%$

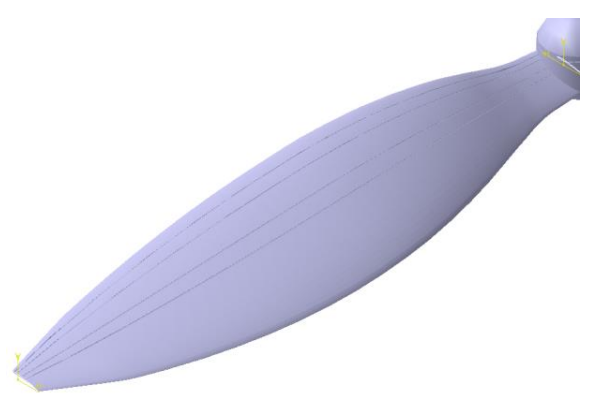

(a)

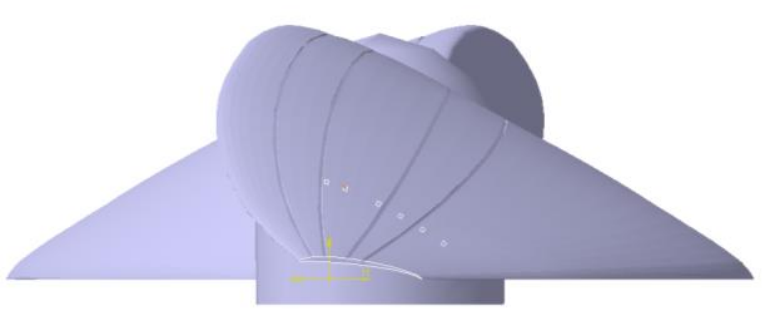

(b)

Figure 5. Schematic of a propeller with slots positioned at $0.09 \mathrm{c}, 0.17 \mathrm{c}, 0.32 \mathrm{c}$ and $0.42 \mathrm{c}$ (a) isometric view (b) front view

\section{RESULTS AND DISCUSSION}

Numerical analyses data were compared with experimental data to validate numerical setup used throughout the study.
The data collected from the numerical analysis are force and moment, which is resolve into three-coordinate system, listed as $\mathrm{x}, \mathrm{y}$ and $\mathrm{z}$. Based on the data collected, thrust coefficient, moment coefficient and efficiency were calculated based on Eqns. (1)-(8) as listed below. Eqns. (1)-(5) describes thrust coefficient, torque coefficient, power coefficient, efficiency and advance ratio respectively. Meanwhile Eqns. (6) and (7) shows percentage change between numerical method and experimental method for thrust and torque respectively.

$$
\begin{gathered}
K_{T}=\frac{T}{\rho n^{2} D^{4}} \\
K_{Q}=\frac{Q}{\rho n^{2} D^{5}} \\
K_{P}=\frac{P}{\rho n^{3} D^{5}} \\
\eta=J \frac{K_{T}}{K_{P}} \\
J=\frac{V}{n D} \\
\Delta K_{T}(\%)=\frac{K_{T_{C F D^{-}} K_{T_{E X P}}}}{K_{T_{E X P}}} \times 100 \\
\Delta K_{P}(\%)=\frac{K_{P_{C F D^{-}} K_{P_{E X P}}}}{K_{P_{E X P}}} \times 100
\end{gathered}
$$

Based on the equations, $\mathrm{T}(\mathrm{N})$ represent thrust, $\mathrm{Q}(\mathrm{Nm})$ is torque, $\mathrm{n}$ (rps) rotational speed of the propeller, D (m) diameter of the propeller, $\rho\left(\mathrm{kgm}^{-3}\right)$ is the operational fluid density.

\subsection{Grid type and turbulence model}

As discussed in Section 3.4, the different grid and turbulence models were tested in this study to determine optimial method to predict the performance of propeller at high accuracy. Table 5 shows the mesh independence summary. Error listed indicates the discrepancy between numerical and experimental method, calculated using Eqns. (6) and (7).

Table 5. Computational results at different mesh resolutions with standard k- $\omega$ Turbulence Model for $\mathrm{J}=0.628$

\begin{tabular}{cccc}
\hline \multirow{2}{*}{ Mesh } & \multicolumn{3}{c}{ Error $(\%)$} \\
\cline { 2 - 4 } & $\mathrm{K}_{\mathrm{T}}$ & $\mathrm{K}_{\mathrm{Q}}$ & Efficiency, $\eta$ \\
\hline Standard & 3.3020 & 2.7723 & 0.5010 \\
Coarse & 2.3817 & 4.1530 & 1.8928 \\
Mid & 3.3282 & 4.0127 & 0.7574 \\
Mid-Fine & 4.4237 & 4.0175 & 0.3795 \\
Fine & 4.3530 & 4.2559 & 0.3795 \\
\hline
\end{tabular}

Based on the analyses, all the meshing method gives satisfactorily results, with error less than $5 \%$. Standard mesh gives optimized results for thrust, torque and efficiency. Meanwhile other meshing shows acceptable results, but with significant difference in torque and efficiency. Thus, standard mesh is utilized throughout the entire study, as the result is sufficient to determine the performance of propeller.

Apart from baseline, the coarsest of mesh, standard mesh is 
also used for meshing the slotted models. The commercial code ANSYS has the capability to produce mesh of high refinement along the slots. An unstructured mesh strategy is also followed for slotted model meshing.

Table 6 shows the results of the analyses with different turbulence model. Standard k- $\omega$ provides more accurate results compared to standard k- $\varepsilon$ and SST k- $\omega$. Standard k- $\omega$ manages to predict the performance for low Reynolds number applications. Thus, this turbulence model is further used throughout the analysis for this study. For the standard k- $\omega$ model, in the case of unstructured mesh the wall $\mathrm{y}+$ to be maintained at propeller wall should be less than 300 [26]. The $\mathrm{y}+$ of all nodal points of propeller geometry lies in the acceptable range of between 0 and 30 .

Figure 6 illustrate the results of thrust coefficient, power coefficient and efficiency with a range of advance ratio for numerical analysis and experimental method. Based on the result, the accuracy varies with advance ratio. For thrust coefficient, at low advance ratio, the result shows slight underprediction, and the discrepancy decreases as advance ratio increase up until advance ratio of 0.659 . The remaining advance ratio shows slight over-prediction of the analysis.

Table 6. Computational results with different turbulence model for $\mathrm{J}=0.628$

\begin{tabular}{cccc}
\hline \multirow{2}{*}{ Turbulence Model } & \multicolumn{3}{c}{ Error (\%) } \\
\cline { 2 - 4 } & $\mathrm{K}_{\mathrm{T}}$ & $\mathrm{K}_{\mathrm{Q}}$ & Efficiency, $\eta$ \\
\hline Standard k- $\varepsilon$ & 2.3817 & 4.1530 & 1.8928 \\
Standard k- $\omega$ & 2.6997 & 2.9662 & 0.3187 \\
SST k- $\omega$ & 3.4175 & 3.8805 & 0.5258 \\
\hline
\end{tabular}

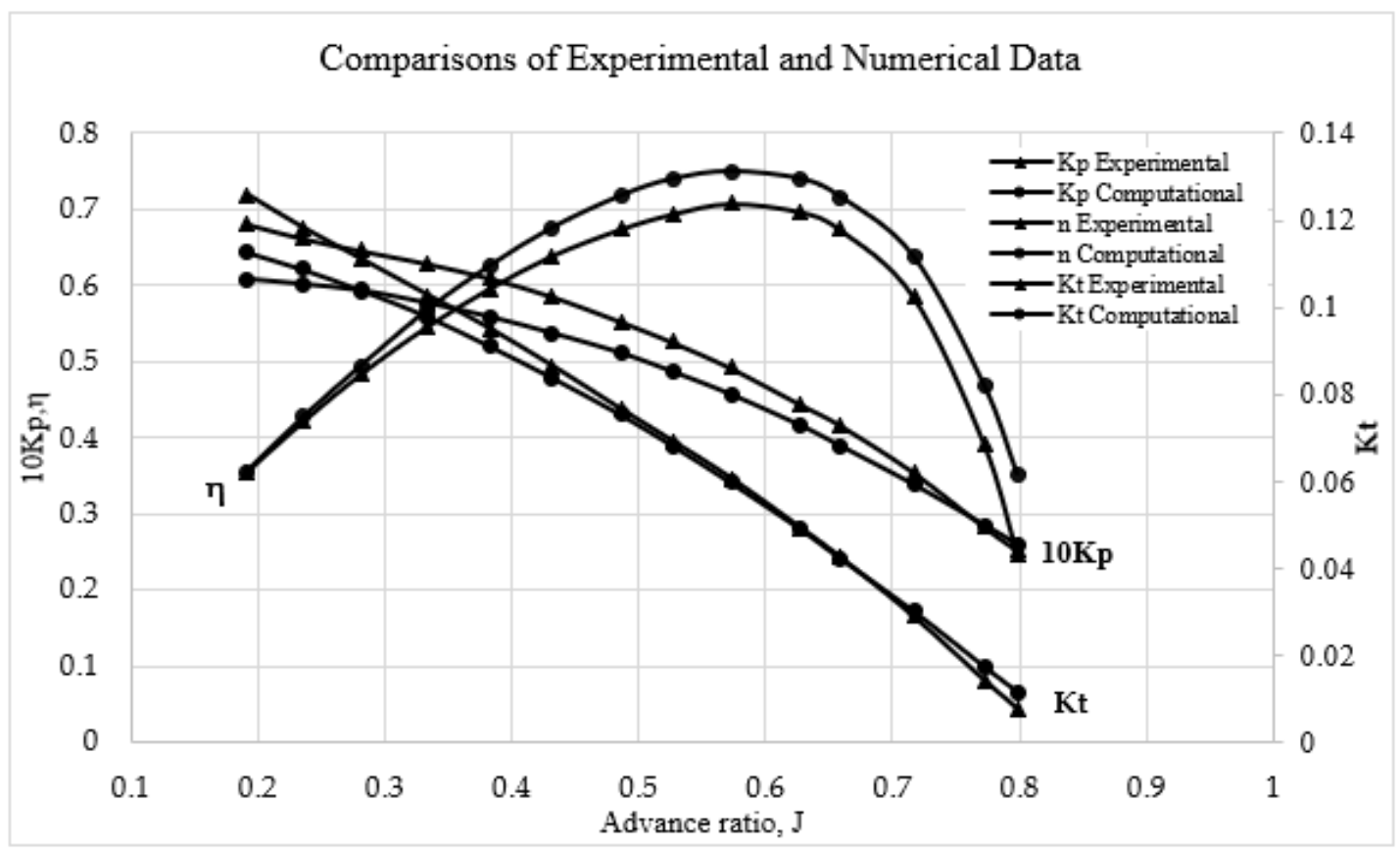

Figure 6. Comparisons of thrust coefficient, power coefficient, and efficiency for baseline design

In addition, power coefficient also shows similar pattern. In which for lower advance ratio, the result shows underprediction compared to experimental results. Highest difference can be observed for advance ratio of 0.192 , with $10.75 \%$.

In contrast, efficiency shows over-prediction over the whole range of advance ratio. This is because advance ratio is the function of thrust coefficient and power coefficient. In general, the discrepancy increases as the advance ratio increase. Thus, the highest difference can be observed at advance ratio of 0.799 , with difference of $42.5 \%$ from the experimental result.

\subsection{Effect of slot position}

The performance of slotted propeller blade is affected by the slot position. The dimension of the slot is constant, whereas the position is varied at $12.5 \%$ chord from leading edge to trailing edge. The analysis is carried out for seven slotted positions which include $12.5 \%, 25 \%, 32.5 \%, 50 \%, 62.5 \%$, $75 \%$ and $87.5 \%$.

Figure 7, Figure 8 and Figure 9 illustrate the results for the analysis for thrust coefficient, power coefficient, and efficiency respectively for various slot positions compared to baseline configuration design.

For slot $12.5 \%$, the thrust coefficient for slotted design is higher than thrust coefficient of baseline design. Increment in thrust can be observed for lower advance ratio, from 0.192 to 0.573 , with increment with the range of $0.5 \%$ to $2.44 \%$. Highest increment can be observed for advance ratio of 0.383 , with difference of $2.44 \%$. The remaining advance ratio shows decrement in thrust coefficient. However, with increment of thrust coefficient, power coefficient also increases, with range of $10.38 \%$ to $33.3 \%$.

For slot $25 \%$ from the leading edge, the thrust coefficients are higher than the baseline configuration. The result shows maximum difference of $3.10 \%$ for advance ratio of 0.192 . Increment in thrust coefficient can be observed up to advance ratio of 0.573 with range of $0.21 \%$ to $3.10 \%$. From advance ratio of 0.628 to 0.799 the thrust coefficient performance deteriorates. In addition, increment in power coefficient can also be observed for the whole range of advance ratio, with maximum of $44.59 \%$. 


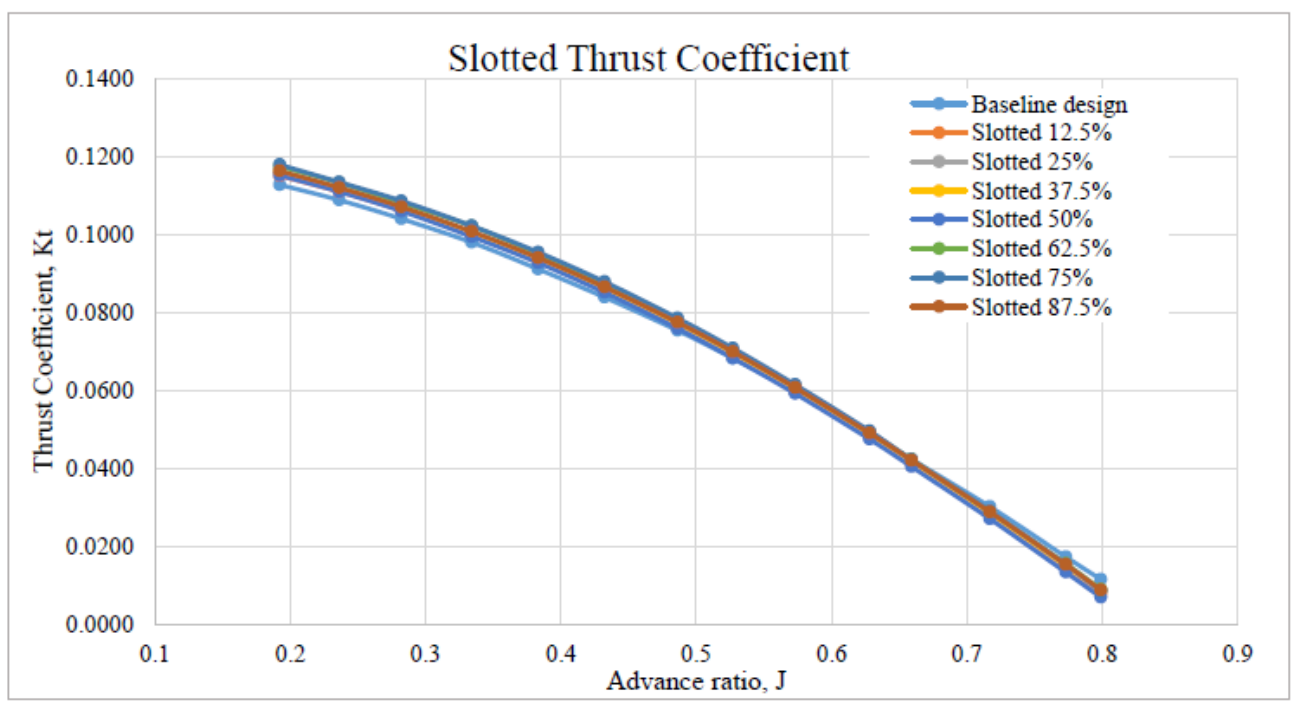

Figure 7. Thrust coefficient for slotted blade design for various slot position

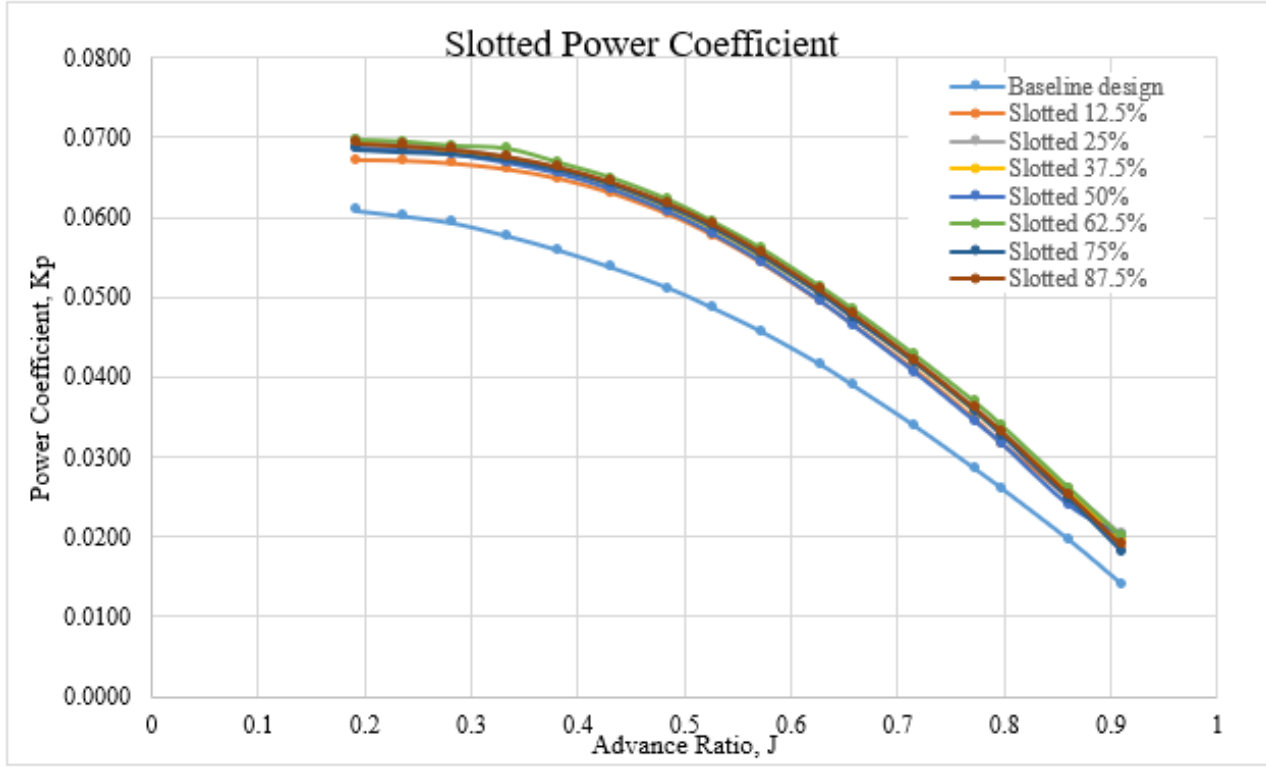

Figure 8. Power coefficient for slotted blade design for various positions

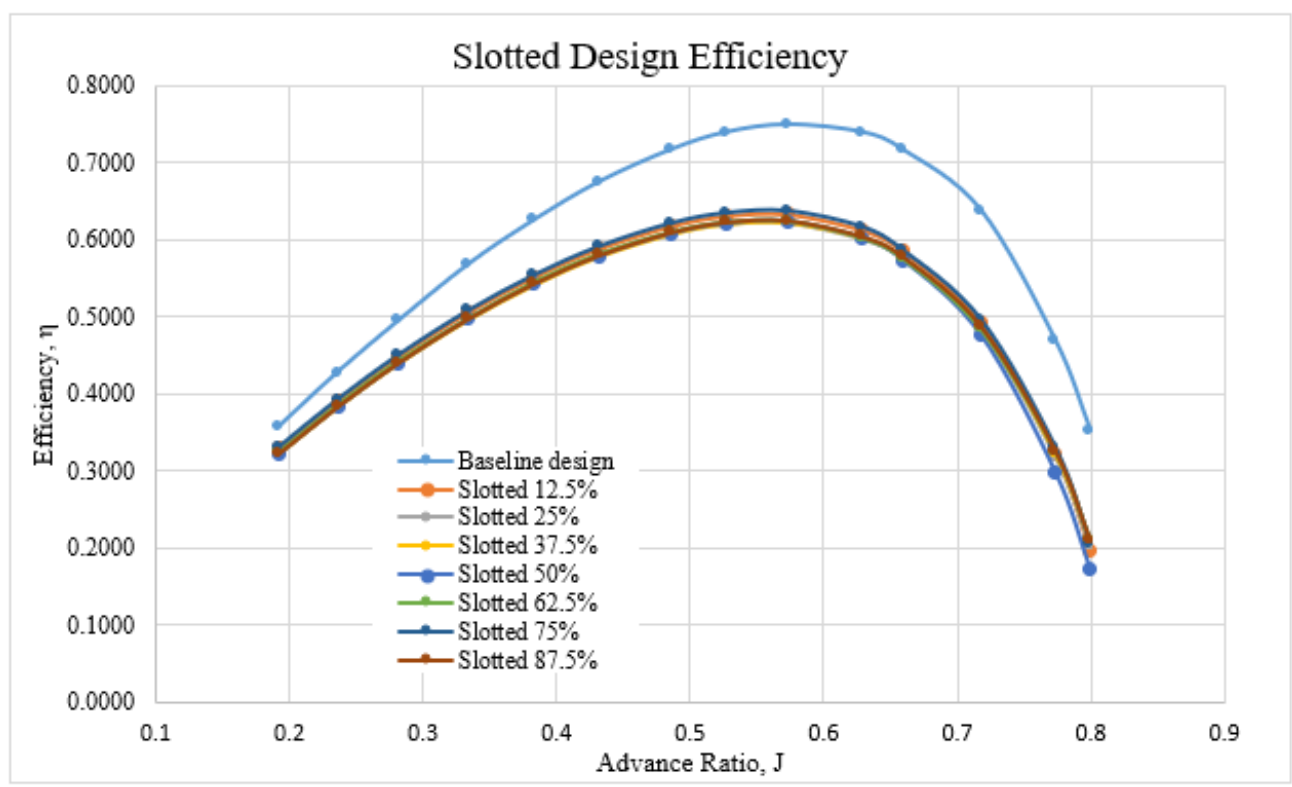

Figure 9. Efficiency for slotted blade design for various positions 
For slot $37.5 \%$, similar behaviour can be observed in which the thrust coefficient over-performed thrust-coefficient for baseline design. Maximum difference between slotted design and baseline occurs for advance ratio of 0.192 , by $2.87 \%$. The power coefficient also increases within range of 13.97 to 39.12 compared to baseline design.

For slot $50 \%$, increase in thrust coefficient can be observed with range of $0.1 \%$ to $2.16 \%$ compared to baseline design within aspect ratio of 0.192 and 0.573 . The thrust coefficient reduces starting from advance ratio of 0.573 . In addition, similar with other design, increase in thrust is also accompanied by increase in power coefficient with range of $12.87 \%$ to $44.03 \%$.

For slot $62.5 \%$, the maximum thrust generated increase by $4.27 \%$ at advance ratio of 0.334 . Increment in thrust coefficient can be observed for a wider range of advance ratio, which is from 0.192 to 0.628 . The remaining advance ratio shows reduction in thrust coefficient as well.

For slot $75 \%$, the slotted design shows the highest increment in thrust coefficient compared to other slotted design, with $4,74 \%$ with respect to baseline configuration. The design shows increment with range of $1.34 \%$ to $4.74 \%$ for advance ratio of 0.192 to 0.628 . Similar increment pattern can be observed for power coefficient.

For slot $87.5 \%$, slotted design also shows increment compared to baseline configuration with maximum increase of $3.18 \%$ and minimum increment of $0.13 \%$. Furthermore, power coefficient for slotted design is higher than baseline design approximately around $13.93 \%$ to $36.14 \%$.

Based on the results discussed above, slotted propeller blade design suggested manages to improve the thrust coefficient for a range of lower advance ratio, ranging from 0.192 to 0.628 . However, increment in power coefficient lead to reduction of propeller efficiency as shown in Figure 8. This is because propeller efficiency is directly influenced with thrust and power coefficient, in which increase in thrust and decrease in power coefficient is expected. This is because of the fluid passing through the slot might not be able to be pushed back into the flow as flow injector, to prevent flow separation on the blade. Thus, more detailed analysis needs to be done to determine the best combinations between slot locations, and width that will contribute in overall performance improvements of slotted propeller blade design.

\subsection{Pressure distribution on the propeller blade}

Each propeller experiences different pressure distribution based on the operational condition. From ANSYS Fluent, the pressure distribution contour is generated, and the pressure will be further used for static structural analysis. Maximum and minimum pressure data is tabulated in Table 7.

Figure 10 shows the pressure contour for the propeller blade obtained from CFD analysis. Each of the propeller blade experience different pressure magnitude which causes stress distribution variation along the body. Based on the figure, it can be seen clearly that the pressure at the back side of the propeller is slightly higher than the pressure at the front side of the propeller. This condition is similar as aircraft wing, in which pressure at the bottom of the wing is higher than the top side of the wing, which creates pressure difference that will generate lift for the aircraft. Meanwhile for propeller blade, pressure difference between the front side and back side of propeller blade creates force in forward direction, known as thrust. From the figure, it can observe that negative pressure occurs; this is due to pressure gradient that is solved using Navier Stokes equation.

Overall pressure distribution for the propeller blade is considerably uniform at the front section along the blade, compared to the back section. In addition, leading edge experience higher pressure than trailing edge, due to flow stagnation point. It is also shown that the freestream speed (advance ratio) greatly influences blade pressure distribution, where the higher the freestream velocity, the lower the pressure difference subjected along the blade.

For freestream velocity of $2.4384 \mathrm{~m} / \mathrm{s}(\mathrm{J}=0.192)$, highest pressure reaches $368 \mathrm{~Pa}$ at the back section of the blade. In addition, at freestream velocity of $5.4864 \mathrm{~m} / \mathrm{s}$, the highest pressure observed is $574 \mathrm{~Pa}$. At higher freestream velocity, high pressure continuously occurred along the blade, especially around the trailing edge of the blade.

Table 7. Maximum and minimum pressure for slotted design

\begin{tabular}{ccc}
\hline & \multicolumn{2}{c}{ Pressure $(\mathrm{Pa})$} \\
\hline 2.4384 & 367.883 & -1200.492 \\
2.9972 & 382.058 & -1123.83 \\
3.5814 & 424.734 & -1027.585 \\
4.2418 & 486.911 & -911.93 \\
4.8641 & 545.619 & -804.095 \\
5.4864 & 573.907 & -763.379 \\
6.1722 & 623.478 & -886.671 \\
6.6929 & 654.779 & -1038.651 \\
7.2771 & 692.335 & -1194.568 \\
7.9756 & 750.041 & -1338.229 \\
8.3693 & 766.522 & -1392.7 \\
9.1059 & 791.286 & -1422.495 \\
9.8171 & 809.253 & -1423.814 \\
10.1473 & 819.555 & -1418.001 \\
\hline
\end{tabular}

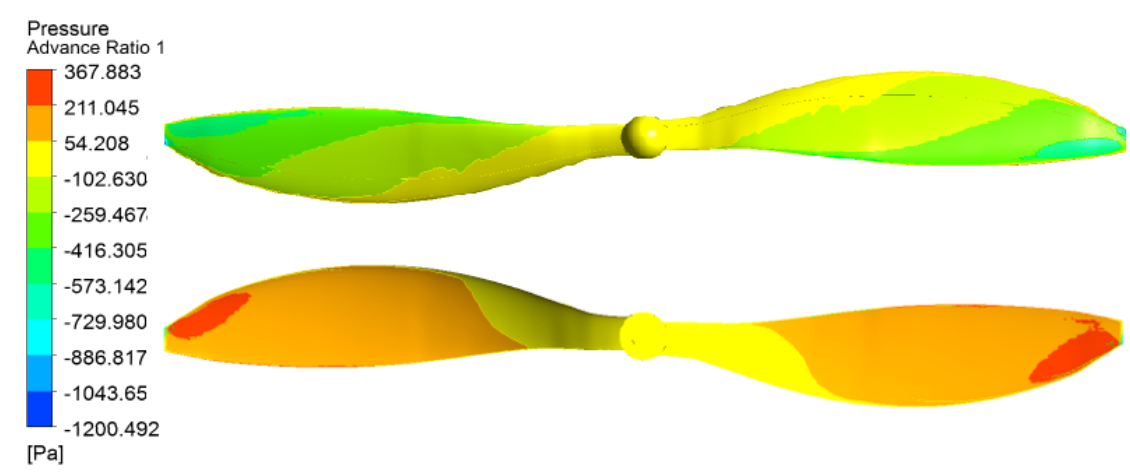


Pressure

382.058

231.469

80.880

$-69.709$

$-220.297$

$-370.886$

$-521.475$

$-672.063$

$-822.652$

$-973.241$

[Pa]

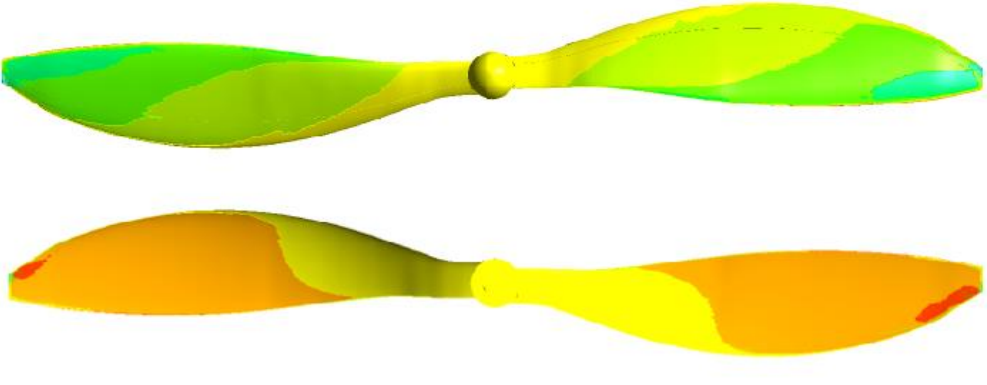

(b)

Pressure
Advance Ratio 3

T24.734

279.502

134.270

$-10.962$

$-156.194$

$-301.426$

$-446.657$

$-591.889$

$-737.121$

$-882.353$

$-1027.585$

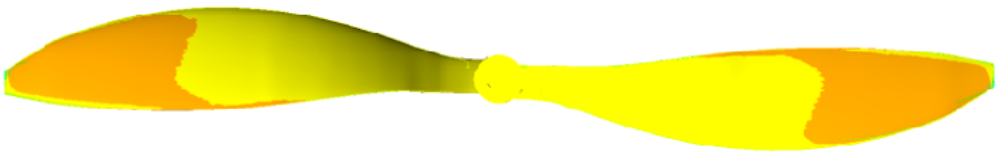

(c)

Pressure

486.911

486.911
347.027

207.143

$-67.259$

$-72.625$

$-212.509$

$-352.393$

$-492.278$

$-632.161$

$-772.046$

$-911.930$

[Pa]

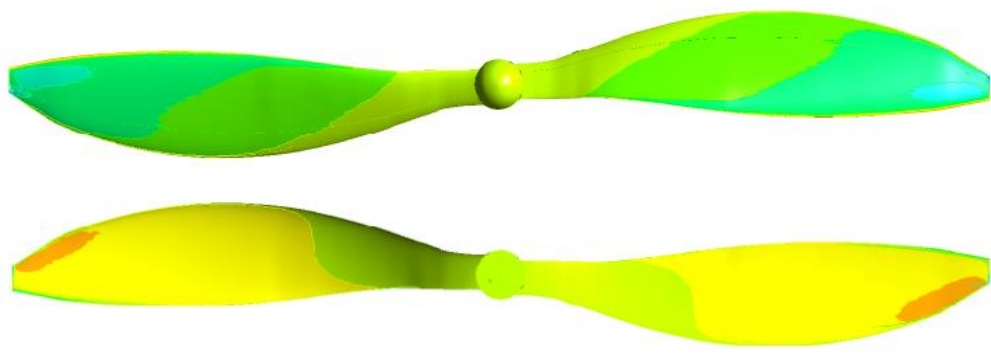

(d)

Pressure
Advance Ratio 5

T 545.619

410.647

275.676

$-140.705$

5.733

$-129.238$

$-264.209$

$-399.181$

$-534.152$

$-669.123$

$-804.095$

[Pa]

Pressure

Advance Ratio
573.907

573.907
-442.878

$-311.850$

180.822

49.793

$-81.235$

$-212.264$

$-343.292$

$-474.321$

$-605.349$

$-736.378$
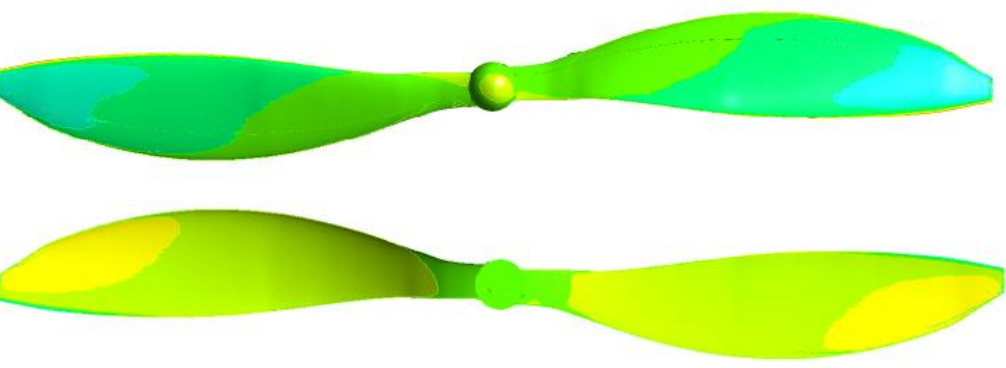

(e)

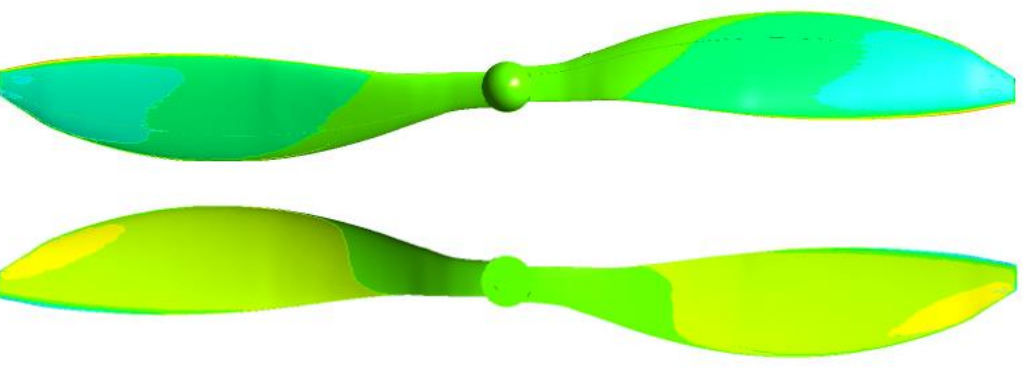

(f) 
$-472.463$

$-321.448$

$-170.434$

19.419

$-131.596$

$-282.611$

$-433.626$

$-584.641$

$-735.656$

$-886.671$

[Pa]

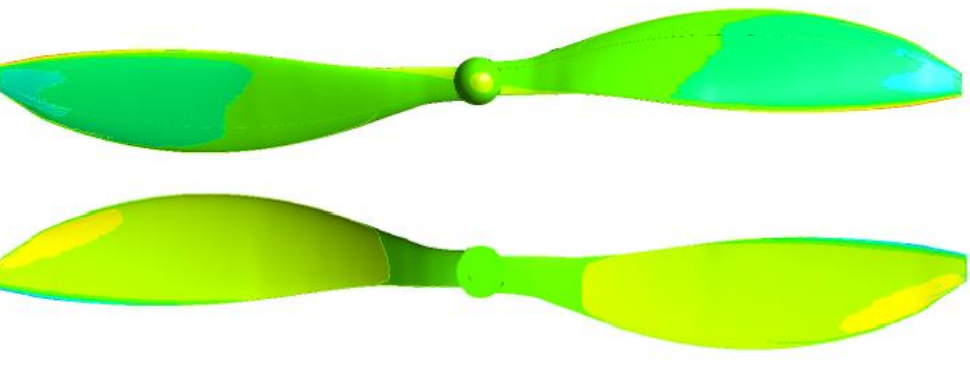

(g)

Pressure

485.436

316.093

146.75

$-22.593$

$-191.936$

$-361.279$

$-530.622$

$-699.965$

$-869.308$

[Pa]

$-1038.651$

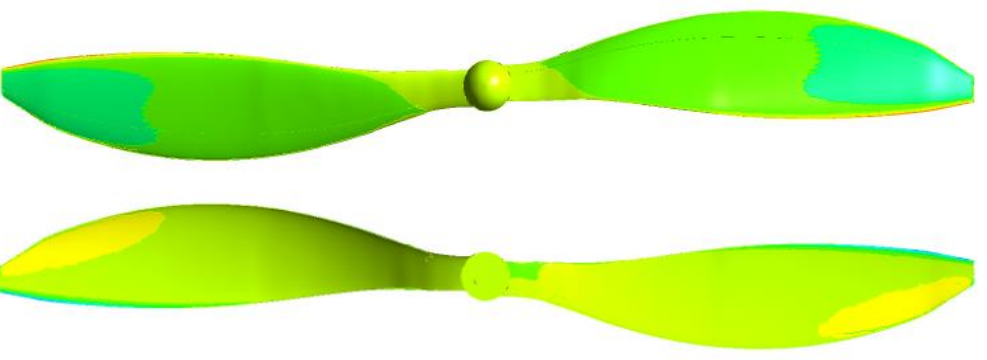

(h)

Pressure

692.335
503.645

314.954

126.264

$-62.426$

$-251.117$

$-439.807$

$-628.497$

$-817.187$

$-1005.878$

$-1194.568$

[Pa]

Pressure
Advance Ratio 10

Advance Ratio

750.041

541.214
-332.387

332.387
-123.560

$-85.267$

$-294.094$

$-502.921$

$-711.748$

$-920.575$

$-1129.402$

$[\mathrm{Pa}]$

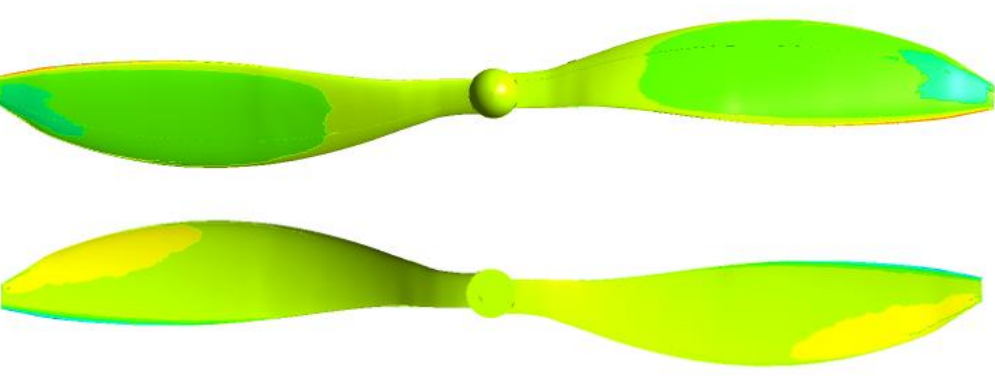

(i)

Pressure

Advance Ratio 11

766.522

550.600

334.678

118.755

$-97.167$

$-313.089$

$-529.011$

$-744.933$

$-960.856$

$-1176.778$

$-1392.700$

[Pa]

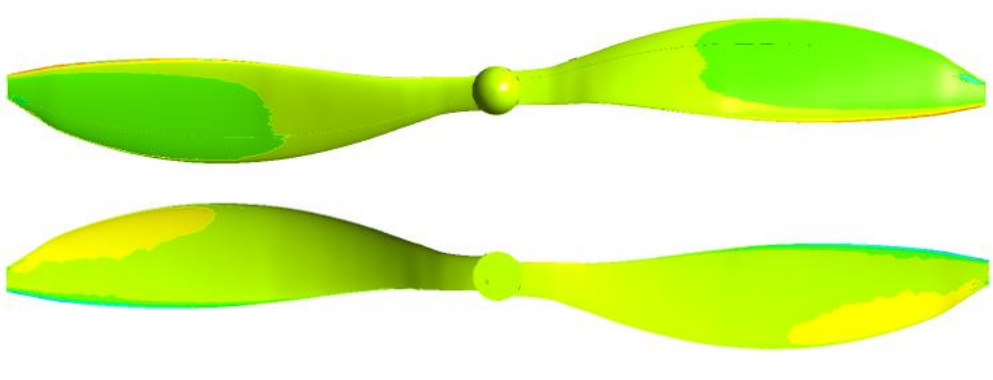

(j)
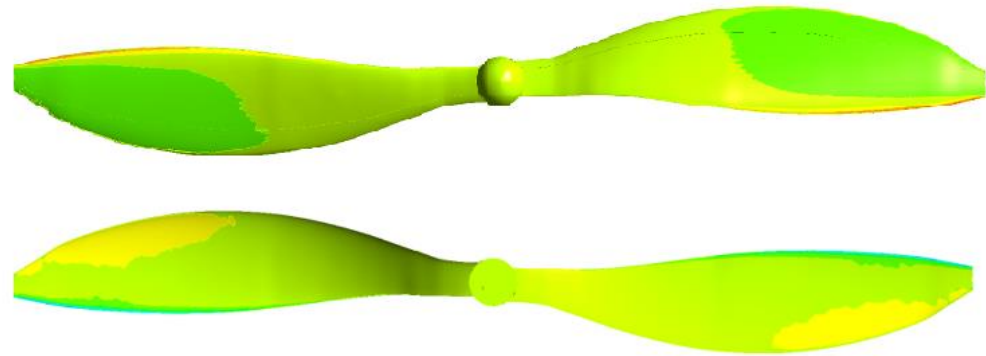

(k) 


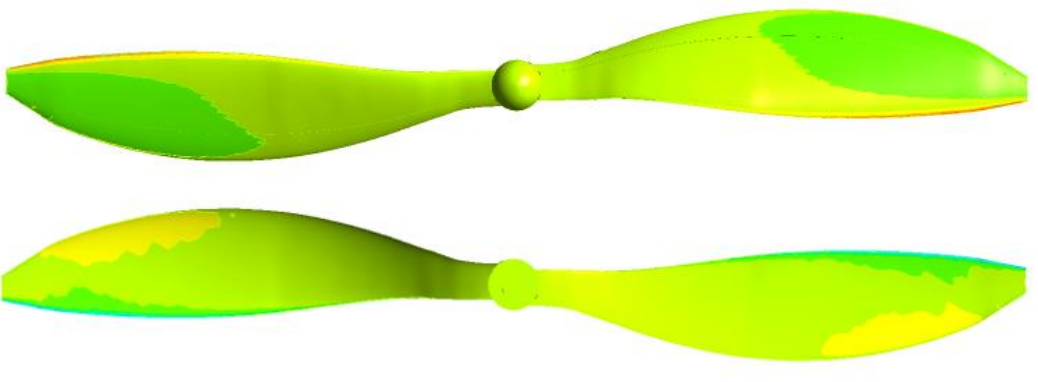

(1)
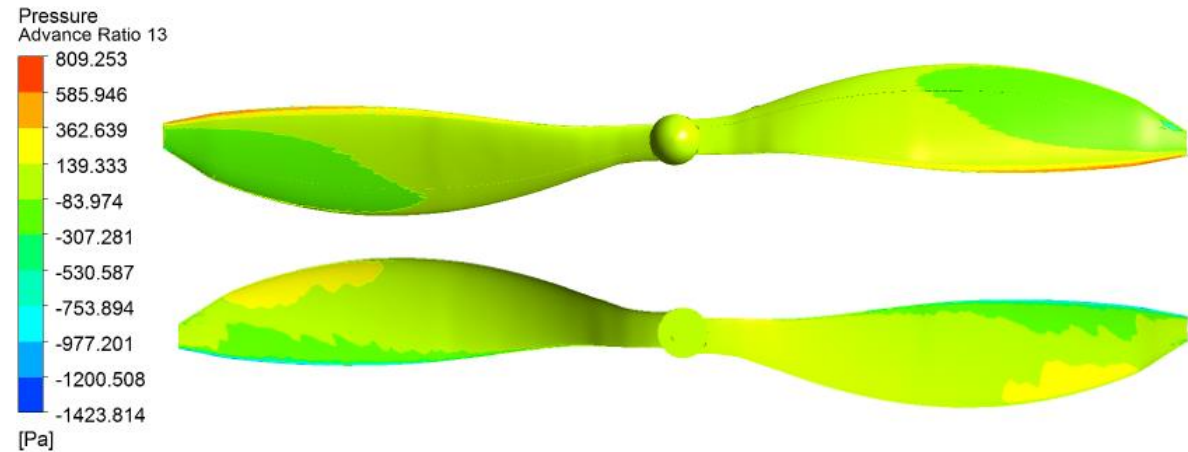

(m)
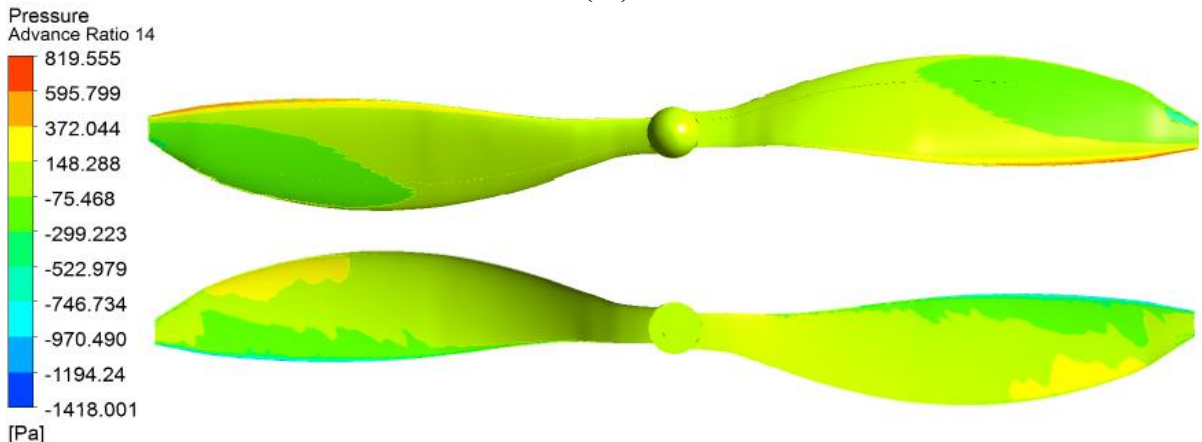

(n)

Figure 10. (a)-(n) Propeller blade pressure distribution at various free stream velocity. (Top) Pressure at the front side. (Bottom) Pressure at the back side

\subsection{Stress distribution and deformation of propeller blade}

Stress analysis was conducted by using ANSYS Static Structural Mechanical analysis. Structural analyses were conducted to estimate and verify structural behavior of the propeller blade subjected to pressure during operation. Blade stress distribution is shown in Figure 11.
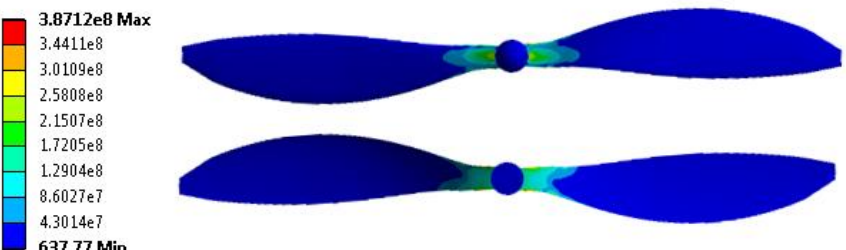

Figure 11. Propeller blade stress distribution. (Top) Front section (Bottom) Back section at free stream velocity of $2.4384 \mathrm{~m} / \mathrm{s}$

The results for structural analysis in terms of maximum stress, maximum strain and total deformation are tabulated in
Table 8. Only one figure is shown in Figure 11, for freestream velocity of $2.4834 \mathrm{~m} / \mathrm{s}$ for explanation purposes. Based on the figure, the stress is concentrated on the hub, near to blade root. In addition, the stress decreases with increase of radial distance from hub to blade tip. Stress acted on propeller blade is highly influenced by the freestream velocity.

For this analysis, the material selected will break under stress of $250 \mathrm{MPa}$. Thus, based on the results, the propeller will be subjected to material failure when freestream velocity is below $6.6929 \mathrm{~m} / \mathrm{s}$. This is because stress due to pressure during operation exceeds the designated stress at break. The propeller blade will be reliable for the remaining operational freestream velocity. In addition, the material will fail when the material exceed strain at $1.58 \%$. Thus, based on this condition, it is suggested that the slotted propeller blade to only be operated below $6.6929 \mathrm{~m} / \mathrm{s}$ as it will not exceed both stress and strain at break.

Propeller blade will undergo deflection due to the load acted along the blade surface. As expected, the deformation is concentrated on the tip of propeller blade. However, the blade material is not rigid enough to hold the shape under operational conditions, as the deformation range is so high. 
Therefore, the propeller blade has higher tendency to deflect which may cause changes in propeller performance. To overcome this issue, different material with higher rigidity may be tested.

Table 8. Summary for static structural analysis

\begin{tabular}{cccc}
\hline $\begin{array}{c}\text { Free } \\
\text { stream } \\
\text { velocity } \\
(\mathrm{m} / \mathrm{s})\end{array}$ & $\begin{array}{c}\text { Maximum } \\
\text { Von-Mises } \\
\text { Stress }(\mathrm{MPa})\end{array}$ & $\begin{array}{c}\text { Maximum } \\
\text { Von-Mises } \\
\text { Strain }(\%)\end{array}$ & $\begin{array}{c}\text { Total } \\
\text { Deformation } \\
(\mathrm{m})\end{array}$ \\
\hline 2.4384 & 387.12 & 1.9863 & 0.055347 \\
2.9972 & 374.15 & 1.9197 & 0.053409 \\
3.5814 & 359.95 & 1.8469 & 0.051281 \\
4.2418 & 340.36 & 1.7463 & 0.048358 \\
4.8641 & 319.05 & 1.6372 & 0.04517 \\
5.4864 & 303.67 & 1.5591 & 0.042907 \\
6.1722 & 266.59 & 1.368 & 0.037437 \\
6.6929 & 258.82 & 1.3288 & 0.036248 \\
7.2771 & 233.9 & 1.2004 & 0.032578 \\
7.9756 & 199.2 & 1.0227 & 0.02748 \\
8.3693 & 181.3 & 0.93288 & 0.02453 \\
9.1059 & 139.7 & 0.71721 & 0.018801 \\
9.8171 & 99.656 & 0.51163 & 0.013017 \\
10.1473 & 81.124 & 0.41649 & 0.010343 \\
\hline
\end{tabular}

\section{CONCLUSIONS}

In this study, the performance of novel slotted propeller blade design is analyzed and compared with baseline APC Slow Flyer 10' x 7' propeller blade. In the analyses, the aerodynamic performance of the propeller blade is tested and the results show a desirable increase in thrust ranging from $0.1 \%$ to $4.74 \%$. However, increase in thrust is also accompanied by increase in power coefficient, which reduces the overall efficiencies of the propeller blade. This is because propeller efficiency is directly influenced by thrust and power, which can be obtained by increase in thrust, decrease in power coefficient or both. Based on these results, further optimization is required to focus on decrease in power coefficient to ensure overall increase in propeller performance.

In addition, this study also presents the pressure and stress distribution study for structural integrity of the propeller blade. Based on the analyses, novel slotted propeller blade design managed to maintain its structural strength under during operation below that $6.6929 \mathrm{~m} / \mathrm{s}$ as it will not exceed both stress and strain at break. Meanwhile for deformation, higher rigidity material should be tested as the current material used in the analyses is not able to sustain the shape under operational condition.

More analyses need to be performed in terms of novel propeller blade design with combination of suitable material. Therefore, high efficiency propeller blade design with high capability to sustain load under operational conditions can be achieved.

\section{REFERENCES}

[1] Kontogiannis, S.G., Ekaterinaris, J.A. (2013). Design, performance evaluation and optimization of a UAV. Aerosp. Sci. Technol., 29(1): 339-350. https://doi.org/10.1016/j.ast.2013.04.005

[2] Finn, R.L., Wright, D. (2012). Unmanned aircraft systems: Surveillance, ethics and privacy in civil applications. Comput. Law Secur. Rev., 28(2): 184-194. https://doi.org/10.1016/j.clsr.2012.01.005

[3] Pajares, G. (2015). Overview and current status of remote sensing applications based on unmanned aerial vehicles (UAVs). Photogramm. Eng. Remote Sens., 81(April): 281-330 https://doi.org/10.14358/PERS.81.4.281

[4] Watts, H.C. (1920). The Design of Screw Propellers: With Special Reference to Their Adaptation for Aircraft. First. Forgotten Books.

[5] Wald, Q.R. (2006). The aerodynamics of propellers. Prog. Aerosp. Sci., 42(2): 85-128. https://doi.org/10.1016/j.paerosci.2006.04.001

[6] Liu, X., Jawahar, H., Azarpeyvand, M., Theunissen, R. (2015). Aerodynamic and Aeroacoustic Performance of Serrated Airfoils. 21st AIAA/CEAS Aeroacoustics Conf., pp. 1-16. https://doi.org/10.2514/6.2015-2201

[7] Chong, T.P., Vathylakis, A. (2015). On the aeroacoustic and flow structures developed on a flat plate with a serrated sawtooth trailing edge. J. Sound Vib., 354: 6590. https://doi.org/10.1016/j.jsv.2015.05.019

[8] Ibrahim, M., Alsultan, A., Shen, S., Amano, R.S. (2015). Advances in horizontal axis wind turbine blade designs: introduction of slots and tubercle. J. Energy Resour. Technol., 137(5):

https://doi.org/10.1115/1.4030399

51205.

[9] Lin, S.Y., Lin, Y.Y., Bai, C.J., Wang, W.C. (2016). Performance analysis of vertical-axis-wind-turbine blade with modified trailing edge through computational fluid dynamics. Renew. Energy, 99: 654-662. https://doi.org/10.1016/j.renene.2016.07.050

[10] Belamadi, R., Djemili, A., Ilinca, A., Mdouki, R. (2016). Aerodynamic performance analysis of slotted airfoils for application to wind turbine blades. J. Wind Eng. Ind. Aerodyn., 151: 79-99. https://doi.org/10.1016/j.jweia.2016.01.011

[11] Linfield, W., Kevin, Mudry, R.G. (2008). Pros and Cons of CFD and Physical Flow Modeling.

[12] Blazek, J. (2001). Computational Fluid Dynamics: Principle and Applications. First Edit. Baden-Daettwil, Switzerland: Elsevier.

[13] Anderson, J.D. (1995). Computational Fluid Dynamics the Basics with Applications. 1st ed. New York: McGraw-Hill.

[14] Brandt, J.B., Selig, M.S. (2011). Propeller performance data at low Reynolds numbers. 49th AIAA Aerosp. Sci. Meet., pp. 1-18. 10.2514/6.2011-1255

[15] Deters, R.W., Ananda Krishnan, G.K., Selig, M.S. (2014). Reynolds number effects on the performance of small-scale propellers. In 32nd AIAA Applied Aerodynamics Conference, pp. 1-18. 10.2514/6.20142151

[16] Subhas, S. (2012). CFD analysis of a propeller flow and cavitation. Int. J. Comput. Appl., 55(16): 26-33. 10.5120/8841-3125

[17] Wang, X., Walters, K. (2012). Computational analysis of marine-propeller performance using transition-sensitive turbulence modeling. J. Fluids Eng., 134(7): 71107-171107-10. https://doi.org/10.1115/1.4005729

[18] Ernesto Benini, Ã. (2004). Significance of blade element theory in performance prediction of marine propellers. Ocean Eng., 31: 957-974. https://doi.org/10.1016/j.oceaneng.2003.12.001

[19] Tian, W., Song, B., Van Zwieten, J.H., Pyakurel, P. 
(2015). Computational fluid dynamics prediction of a modified savonius wind turbine with novel blade shapes. Energies, 8(8): 7915-7929. 10.3390/en8087915

[20] Rao Seetharama, Y., Rao Mallikarjuna, K., Sridhar Reddy, B. (2012). Stress analysis of composite propeller by using finite element analysis. Int. J. Eng. Sci. Technol., 4(8): 3866-3875.

[21] Yeo, K.B., Choong, W.H., Hau, W.Y. (2014). Prediction of propeller blade stress distribution through FEA. J. Appl. Sci., 14(22): 3046-3054. http://dx.doi.org/10.3923/jas.2014.3046.3054

[22] Das, H.N., Rao, P.V., Suryanarayana, C., Kapuria, S. (2013). Effect of structural deformation on performance of marine propeller. J. Marit. Res., X(3): 47-50.

[23] Sunkara, J.K., Rao, S., Kumar Babu, P. (2015). FEM Analysis on submarine propeller blade for improved efficiency by using solid works and ANSYS-workbench. Int. J. Emerg. Eng. Res. Technol., 3(11): 144-151.

[24] Brandt, J.B., Deters, R.W., Ananda, G.K., Selig, M.S. (2016). UIUC propeller data site. http://mselig.ae.illinois.edu/props/propDB.html, accessed on
Nov. 1, 2016.

[25] Corporation, C. Celanese Technical Data. https://www.celanese.com/, accessed on Feb. 23, 2016.

[26] ANSYS (2014). Lecture 7: Turbulence Modeling, Introduction to ANSYS Fluent. ANSYS, Inc., p. 46.

\section{NOMENCLATURE}

$\mathrm{T}$

Q

$\mathrm{n}$

$\mathrm{D}$

$\mathrm{J}$

$\mathrm{K}_{\mathrm{T}}$

$\mathrm{K}_{\mathrm{Q}}$

\section{Greek symbols}

$\rho$

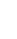

thrust, $\mathrm{N}$

torque, $\mathrm{Nm}$

rotational speed of propeller, rps

diameter of propeller, $\mathrm{m}$

advance ratio

thrust coefficient

torque coefficient density, $\mathrm{kg} \cdot \mathrm{m}^{-3}$ 